\title{
Thermomechanical Properties of Carbon Fabric Reinforced Epoxy Laminates with h-BN and $\mathrm{MoS}_{2}$ Fillers
}

\author{
Yermal Shriraj Rao ${ }^{a}$ Basavannadevaru Shivamurthy ${ }^{a}$ (D), Nagaraja Shetty ${ }^{a}$, \\ Nanjangud Subbarao Mohan ${ }^{a}$ (1D

\begin{abstract}
${ }^{a}$ Manipal Institute of Technology, Manipal Academy of Higher Education, Department of Mechanical and Manufacturing Engineering, Manipal-576 104, India.
\end{abstract}

Received: May 04, 2021; Revised: July 17, 2021; Accepted: August 04, 2021

\begin{abstract}
This work endeavors to investigate thermomechanical performance of carbon fabric reinforced epoxy composite (CEC) with fillers - hexagonal boron nitride (h-BN) and molybdenum disulfide $\left(\mathrm{MoS}_{2}\right)$. The filler of 2, 4, 6, and $8 \mathrm{Wt} . \%$ was dispersed precisely in the epoxy resin through magnetic stirring and ultrasonication, prepared the filler loaded CEC using vacuum bag technique and studied the composite behavior at an elevated temperature by dynamic mechanical analysis. The $6 \mathrm{Wt} . \%$ $\mathrm{MoS}_{2}$-CEC showed $70 \%$ enhancement of storage modulus since the filler in the epoxy networks increased the composite stiffness. The increase in G-band intensity of Raman spectra in the filler loaded composites confirmed the improved matrix-fiber stress transfer. The $4 \mathrm{Wt} . \% \mathrm{BN}-\mathrm{CEC}$ revealed the highest glass-transition temperature $92^{\circ} \mathrm{C}$. The thermogravimetric analysis of the composite exhibited a two-step thermal decomposition: epoxy matrix (nearby $260^{\circ} \mathrm{C}$ ) and carbon fibers (beyond $420^{\circ} \mathrm{C}$ ). The $4 \mathrm{Wt} . \% \mathrm{MoS}_{2}-\mathrm{CEC}$ showed the maximum degree of crosslinking, twice the neat CEC, the $\mathrm{MoS}_{2}$ restrained the mobility of the epoxy chains and decreased the thermal decomposition. Both the filler loaded composites have comparable thermal stability and are significantly improved than the neat CEC. Thus, the composite containing solid lubricant filler up to $6 \mathrm{Wt} . \%$ shall be used for high-temperature applications.
\end{abstract}

Keywords: Boron nitride, Molybdenum disulfide, Glass-transition temperature, Storage modulus, Raman spectroscopy.

\section{Introduction}

Carbon fiber reinforced polymer (CFRP) composites have been used widely for structural applications in aerospace, railways, automobiles, sports, and recreation goods for their exceptional specific strength, modulus, and low thermal expansion ${ }^{1-3}$. Among the thermoset matrices, the epoxy resin is frequently used as a matrix for the advanced composites and it exhibits strong adhesion, low shrinkage, high chemical and heat resistance ${ }^{4-6}$. Similarly, the epoxy smoothly spreads over the carbon fiber surface due to its low viscosity at room temperature compared to many thermoplastic resins ${ }^{7,8}$. However, the epoxy resin exhibits weak resistance towards the crack initiation and propagation resulting in a brittle failure of the carbon epoxy composites ${ }^{9,10}$. The low thermal conductivity of the epoxy accumulates heat which degrades the structural property at the elevated temperature ${ }^{11-13}$.

The phase transition from glassy to rubbery occurs in the polymer matrix at a temperature of glass transition $(\mathrm{Tg})^{14}$. It is also an indicator of the status of curing of the polymer matrix ${ }^{15}$. The polymer composites subjected to a temperature beyond $\mathrm{Tg}$ remarkably reduced their strength, stiffness, fracture toughness. Further, the polymer composite started burning when the temperature was increased, it became char,

*e-mail:ns.mohan@manipal.edu and disintegration took place. Hence, the polymer composite should be operated at a temperature far below the Tg.

The FRP composite in many circumstances is subjected to dynamic loading, wear, and excessive heat. In such cases the thermal stability and thermomechanical properties are essential ${ }^{16}$. In this regard, several researchers paid attention to improve the thermal stability, storage modulus ( $\left.\mathrm{E}^{\prime}\right), \mathrm{Tg}$, and toughness of the epoxy matrix by incorporating the fillers. The commonly used fillers are alumina $\left(\mathrm{Al}_{2} \mathrm{O}_{3}\right)^{17}$, boron carbide $\left(\mathrm{B}_{4} \mathrm{C}\right)^{18}$, silicon dioxide $\left(\mathrm{SiO}_{2}\right)^{19}$, nanoclay ${ }^{20,21}$, graphene ${ }^{22-24}$, boron nitride $(\mathrm{BN})^{25,26}$, molybdenum disulfide $\left(\mathrm{MoS}_{2}\right)^{27,28}$. The thermomechanical properties improvement depends on the type, size, shape, and quality of the filler dispersion. The high filler concentration in polymer matrix creates agglomerations, voids, and poor adhesion. These aspects reduce the structural integrity and in some cases the functional properties of the resulting composites ${ }^{29}$.

Nayak et al. ${ }^{17}$ noticed a decrease in dynamic modulus due to the addition of hybrid metal oxide nanofillers such as $\mathrm{Al}_{2} \mathrm{O}_{3}$ and titanium dioxide $\left(\mathrm{TiO}_{2}\right)$ in the glass fiber reinforced epoxy composite. This was due to the $\mathrm{Al}_{2} \mathrm{O}_{3}$ hindrance for the movement of the epoxy molecules and the agglomeration of fillers in addition to the decreased crosslink between polymer and particles. Also, the authors mentioned that 
the filler concentration of $0.1,0.3$, and $0.7 \mathrm{Wt} . \%$ caused a minor change in $\mathrm{Tg}$ and thermal stability. It is reported in the literature that the addition of $\mathrm{B}_{4} \mathrm{C}$ in the carbon fabric reinforced epoxy composite (CEC) improved its $\mathrm{E}^{\prime}$, loss modulus $\left(E^{\prime \prime}\right)$, and damping factor ${ }^{18}$. The silicon carbide (SiC) also improved $\mathrm{E}^{\prime}$ and $\mathrm{E}^{\prime \prime}$ of the $\mathrm{CEC}$ in addition to the improvement of $\mathrm{Tg}$. However, the $\mathrm{SiC}$ reduced the damping factor of the $\mathrm{CEC}^{30}$. Similar kind of effect was observed when the nano $\mathrm{SiO}_{2}$ was added to the $\mathrm{CEC}^{19}$.

Chowdhury et al. ${ }^{20}$ reported that the addition of montmorillonite nanoclay did not have much effect on the Tg but a positive effect on the $E^{\prime}$ and $E^{\prime \prime}$ of the CEC. Similar observation was noticed by Zhou et al. ${ }^{21}$. Muralidhara et al. ${ }^{22}$ reported that the addition of graphene platelet (GP) in the CEC showed improvement in the $\mathrm{E}^{\prime}$ and damping capacity. However, they stated that the GP did not favor in improving the Tg of the composite. Adak et al. ${ }^{31}$ reported that the wrinkled graphene oxide (GO) sheet enhanced the $\mathrm{E}^{\prime}, \mathrm{E}^{\prime \prime}$, and damping. This was attributed to the mechanical interlocking of GO sheet with the epoxy in the composites. Hossain et al. ${ }^{23}$ showed that the addition of amine-functionalized graphene nanoplatelet (f-GNP) enhanced the E', E", crosslink density, and Tg of the CEC. Wan et al. ${ }^{32}$ reported that the silane functionalized graphene oxide (f-GO) improved the $\mathrm{E}^{\prime}$ of epoxy due to reduced mobility of the epoxy matrix in the filler vicinity. The covalent interactions between the f-GO and epoxy chains improved the dynamic property of epoxy composite. Tareq et $\mathrm{al}^{33}$ reported that the nanoclay increased the $\mathrm{E}^{\prime}$ of the CEC. The amino group functionalized graphene improved the $\mathrm{E}^{\prime \prime}$ and toughness of the CEC. However, the hybrid nanoclay-graphene improved the $\mathrm{Tg}$ of the CEC slightly. Loos et al. ${ }^{34}$ demonstrated that randomly oriented single-wall carbon nanotubes (SWCNTs) of $0.25 \mathrm{Wt} \%$ reinforced epoxy resin improved the $\mathrm{E}^{\prime}$ by $16 \%$ due to the rigid and enormous surface area of SWCNTs causing better interactions with the epoxy but it slightly reduced the $\mathrm{Tg}$.

Cai et al. ${ }^{24}$ developed the composites of graphene porous paper reinforced epoxy resin of a single layer and a 15-layer. They found the $\mathrm{E}^{\prime}$ of the 15-layer graphene composite was $170 \%$ higher due to a higher stiffening effect compared to the neat epoxy and single layer graphene composite. Bera et al.$^{35}$ reported that the carbon black $(\mathrm{CB})$ filler in the epoxy increased its $\mathrm{Tg}$ from 68 to $90^{\circ} \mathrm{C}$. This was attributed to the consumption of unreacted monomers on the surface of the CB.

Patki and Goyal ${ }^{25}$ noticed that the addition of $30 \mathrm{Wt} . \%$ hexagonal boron nitride (h-BN) in polyether-ketone (PEK) remarkably improved the $\mathrm{E}^{\prime}, \mathrm{E}^{\prime \prime}$ of the h-BN/PEK composite. However, there was not much change in the Tg. Joy et al. ${ }^{26}$ reported the addition of the filler h-BN improved stiffness and stress transferability of the composite. They found that the epoxy reinforced with $1 \mathrm{Wt} . \% \mathrm{~h}-\mathrm{BN}$ improved the $\mathrm{E}^{\prime}$ up to $11.8 \%$ compared to the neat epoxy. They also mentioned that the $0.25 \mathrm{Wt} \% \mathrm{~h}-\mathrm{BN}$ improved the $\mathrm{Tg}$ by $10^{\circ} \mathrm{C}$. However, the h-BN reinforced epoxy lowered the tan $\delta$ peak height, which confirmed a lesser amount of mobile polymer chains. Madeshwaran et al. ${ }^{27}$ reported a maximum $\mathrm{Tg}$ of $73^{\circ} \mathrm{C}$ for $0.1 \mathrm{Wt} . \%$ exfoliated $\mathrm{MoS}_{2}$ reinforced epoxy composite. This was attributed to the restriction for epoxy chain mobility due to the presence of $\mathrm{MoS}_{2}$. Zhao et al. ${ }^{28}$ reported an increment in the $\mathrm{Tg}$ by $11^{\circ} \mathrm{C}$ and decrement in the $\mathrm{E}^{\prime}$ by $105 \mathrm{MPa}$ for $0.7 \%$ silane functionalized $\mathrm{MoS}_{2}$ reinforced epoxy resin composite.

The h-BN has good thermal shock resistance, chemical stability, wear, and oxidation resistance ${ }^{36-39}$. The thermal conducting and electrically insulating h-BN finds its importance in heat-dissipating nanoelectronics components ${ }^{40}$. The important properties of the $\mathrm{MoS}_{2}$ are lubricious, thermal stability, chemical inertness ${ }^{41}$. They retain lubricative properties even in oxygen-deficient environments and at elevated temperatures $^{42}$. It is found from the literature that these two solid and soft lubricant fillers have the ability to improve the thermomechanical properties of various resins. Hence, we attempted to investigate the thermomechanical properties and thermal stability of the carbon fabric/h-BN/epoxy and the carbon fabric/MoS $/$ /epoxy composites. The material combination and the brief thermomechanical properties of various filler loaded CECs reported in the latest literature have been summarized and presented in Table 1.

\section{Materials and Methods}

\subsection{Material}

The $2 \times 2$ twill weaved carbon fabric (CF) derived from T300 B (TORAYCA ${ }^{\circledR}$ ) grade carbon fiber has been chosen for primary reinforcement. The fabric has 5 yarns per $\mathrm{cm}$ in both the warp and weft, area density- $200 \mathrm{~g} . \mathrm{m}^{-2}$, thickness- $0.3 \mathrm{~mm}$, and number of filaments and yarn fineness are 3000 and 198 tex, respectively. The diglycidyl ether of bisphenol-A (DGBA) epoxy is used with N, N-Bis (2-aminoethyl) ethane1, 2-diamine curing agent as a matrix. The $\mathrm{MoS}_{2}$ and the h-BN solid lubricants are the fillers chosen. The physical and thermal properties of the reinforcement and the matrix materials have been indicated in Table 2 .

\subsection{Composite laminate fabrication}

The calculated quantity of as-bought filler $(2,4,6$, and $8 \mathrm{Wt} . \%$ ) was dispersed in the appropriate quantity of epoxy matrix by magnetic stirring followed by ultrasonication. The magnetic stirring was performed for 20 mins at $500 \mathrm{rpm}$ and maintained $60^{\circ} \mathrm{C}$. Further, the epoxy-filler solution that was blended was sonicated in a probe type ultra-sonicator for about 30 mins keeping the vibration frequency of $20 \mathrm{kHz}$ and the amplitude $35 \%$. In this process, the filler got uniformly mixed with the matrix due to cavitation effect ${ }^{43}$. Afterwards, the stoichiometric quantity of amine-based curing agent (one part of hardener: four parts of resin) was added to the resulting filler-resin mixture and stirred meticulously. This process accelerates the rate of reaction and causes crosslinking. The weight fraction of the epoxy resin, hardener, fillers, and carbon fabric is chosen to prepare different composites as described in Table 3.

Polyvinyl alcohol was applied to the metallic mold as release agent for easy removal of the finished component. The filler dispersed epoxy matrix was manually coated over each successive layer of the carbon fabric. The roller moved over each stacked layer distributed the resin equally and removed air pockets to a certain extent. The same procedure was followed until the desired laminate thickness of approx. 
Table 1. Material combination and brief thermomechanical properties of various filler loaded epoxy-based composites.

\begin{tabular}{|c|c|c|c|c|c|c|c|c|}
\hline \multicolumn{4}{|c|}{ Constituents of samples } & \multicolumn{5}{|c|}{ Thermomechanical properties } \\
\hline $\begin{array}{l}\text { Rein- } \\
\text { forcement in } \\
\text { epoxy }\end{array}$ & Filler & Size & $\begin{array}{l}\text { Quantity } \\
\text { (Wt.\%) }\end{array}$ & $\operatorname{Max} E^{\prime}(\mathrm{MPa})$ & Max E" (MPa) & $\operatorname{Max} \tan \delta$ & $\operatorname{Tg}\left({ }^{\circ} \mathrm{C}\right)$ & Ref. \\
\hline Twill CF & $\mathrm{B}_{4} \mathrm{C}$ & $10 \mu \mathrm{m}$ & $1,3,5$ & $\begin{array}{c}16700 \\
{\left[1 \% \mathrm{~B}_{4} \mathrm{C}\right]}\end{array}$ & $\begin{array}{c}2162 \\
{\left[1 \% \mathrm{~B}_{4} \mathrm{C}\right]}\end{array}$ & $0.95\left[1 \% \mathrm{~B}_{4} \mathrm{C}\right]$ & $97\left[3 \% \mathrm{~B}_{4} \mathrm{C}\right]$ & 18 \\
\hline $\mathrm{CF}$ & $\mathrm{SiC}$ & $5-10 \mu \mathrm{m}$ & 5,10 & $\begin{array}{c}12270 \\
{[5 \% \mathrm{SiC}]}\end{array}$ & $3495[5 \% \mathrm{SiC}]$ & $\begin{array}{c}0.25 * * \\
{[5 \% \mathrm{SiC}]}\end{array}$ & $153[10 \% \mathrm{SiC}]$ & 30 \\
\hline Plain CF & $\mathrm{SiO}_{2}$ & $10-20 \mathrm{~nm}$ & $0.5,1.5,3$ & $\begin{array}{c}18386 \\
{\left[3 \% \mathrm{SiO}_{2}\right]}\end{array}$ & $\begin{array}{c}5136 \\
{\left[0.5 \% \mathrm{SiO}_{2}\right]}\end{array}$ & $\begin{array}{c}0.52 * * \\
{\left[0.5 \% \mathrm{SiO}_{2}\right]}\end{array}$ & $87\left[3 \% \mathrm{SiO}_{2}\right]$ & 19 \\
\hline Carbon fiber & $\mathrm{MoS}_{2}$ & $25 \mu \mathrm{m}$ & 5,10 & $\begin{array}{c}26100 * * \\
{\left[5 \% \mathrm{MoS}_{2}\right]}\end{array}$ & $\begin{array}{c}5300 * * \\
{\left[5 \% \mathrm{MoS}_{2}\right]}\end{array}$ & $\begin{array}{c}0.40 * * \\
{\left[5 \% \mathrm{MoS}_{2}\right]}\end{array}$ & $\begin{array}{c}102 \\
{\left[10 \% \mathrm{MoS}_{2}\right]}\end{array}$ & 42 \\
\hline Plain CF & Clay & $0.3-1 \mu \mathrm{m}$ & $1,2,3$ & $\begin{array}{c}24457 \\
{[2 \% \text { clay }]}\end{array}$ & $\begin{array}{c}3640 \\
{[2 \% \text { clay }]}\end{array}$ & $0.49[2 \%$ clay $]$ & $73[1 \%$ clay $]$ & 20 \\
\hline Plain CF & Clay & Nano size & 2 & $\begin{array}{c}10854 \\
{[2 \% \text { clay }]}\end{array}$ & - & $0.32[2 \%$ clay $]$ & $116[2 \%$ clay $]$ & 21 \\
\hline Twill CF & $\mathrm{G}$ & Nano size & $\begin{array}{c}0.75,1.75 \\
2.75\end{array}$ & $\begin{array}{c}17000 \\
{[1.75 \% \mathrm{G}]}\end{array}$ & $\begin{array}{c}2332 \\
{[0.75 \% \mathrm{G}]}\end{array}$ & $\begin{array}{c}0.97 \\
{[1.75 \% \mathrm{G}]}\end{array}$ & $\begin{array}{c}92 * * \\
{[0.75 \% \mathrm{G}]}\end{array}$ & 22 \\
\hline $\mathrm{CF}$ & $\mathrm{GO}$ & Nano size & $\begin{array}{c}0.05,0.1,0.2 \\
0.4\end{array}$ & $\begin{array}{c}257000 \\
{[0.2 \% \mathrm{GO}]}\end{array}$ & $\begin{array}{c}33970 \\
{[0.2 \% \mathrm{GO}]}\end{array}$ & $\begin{array}{c}0.56 \\
{[0.2 \% \mathrm{GO}]}\end{array}$ & $59[0.2 \% \mathrm{GO}]$ & 31 \\
\hline Satin CF & GNP & $<5 \mathrm{~nm}$ & $\begin{array}{c}0.1,0.2,0.3 \\
0.4,0.5\end{array}$ & $\begin{array}{c}22390 \\
{[0.4 \% \mathrm{GNP}]}\end{array}$ & $\begin{array}{c}1610 \\
{[0.4 \% \text { GNP }]}\end{array}$ & $\begin{array}{c}0.14 \\
{[0.5 \% \mathrm{GNP}]}\end{array}$ & $\begin{array}{c}156 \\
{[0.4 \% \mathrm{GNP}]}\end{array}$ & 23 \\
\hline Satin CF & $\begin{array}{c}\text { Clay, G, } \\
\text { hybrid clay }+\mathrm{G}\end{array}$ & Nano size & $\begin{array}{c}2 \% \text { clay, } \\
0.1 \% \mathrm{G}\end{array}$ & $\begin{array}{c}25280 \\
{[2 \% \text { clay }]}\end{array}$ & $3100[0.1 \% \mathrm{G}]$ & - & $\begin{array}{c}103[2 \% \\
\text { clay+ } 0.1 \% \mathrm{G}]\end{array}$ & 33 \\
\hline Neat epoxy & $\mathrm{GO}, \mathrm{f}-\mathrm{GO}$ & $1-3 \mu \mathrm{m}$ & 0.5 & $\begin{array}{c}2333 \\
{[0.5 \% \mathrm{f}-\mathrm{GO}]}\end{array}$ & - & - & $\begin{array}{c}151 \\
{[0.5 \% \mathrm{f}-\mathrm{GO}]}\end{array}$ & 32 \\
\hline Neat epoxy & Porous G & $5-25 \mu \mathrm{m}$ & - & $\begin{array}{c}7410 \\
{[15-\text {-layer G] }}\end{array}$ & - & $\begin{array}{c}0.28 * * \\
{[15 \text {-layer G] }}\end{array}$ & $\begin{array}{c}108 * * \\
{[1-1 \text {-layer G] }}\end{array}$ & 24 \\
\hline Neat epoxy & $\mathrm{CB}$ & $30 \mathrm{~nm}$ & $1,2,3,4,5$ & - & - & - & $90[4 \% \mathrm{CB}]$ & 35 \\
\hline Neat epoxy & h-BN & $70 \mathrm{~nm}$ & $\begin{array}{c}0.1,0.25 \\
0.5,1\end{array}$ & $\begin{array}{c}2561 \\
{[1 \% \mathrm{~h}-\mathrm{BN}]}\end{array}$ & - & $\begin{array}{c}0.92^{* *} \\
{[1 \% \mathrm{~h}-\mathrm{BN}]}\end{array}$ & $\begin{array}{c}208 \\
{[0.25 \% \mathrm{~h}-\mathrm{BN}]}\end{array}$ & 26 \\
\hline Neat epoxy & $\begin{array}{c}\text { Exfoliated } \\
\mathrm{MoS}_{2}\end{array}$ & Nano size & $\begin{array}{c}0.05,0.1,0.25 \\
0.5\end{array}$ & - & - & - & $\begin{array}{c}73 \\
{\left[0.1 \% \mathrm{MoS}_{2}\right]}\end{array}$ & 27 \\
\hline Neat epoxy & Clay & Nano size & $1,2,3,4$ & $\begin{array}{c}1657 \\
{[2 \% \text { clay }]}\end{array}$ & - & $\begin{array}{c}0.76 * * \\
{[2 \% \text { clay }]}\end{array}$ & $120[2 \%$ clay $]$ & 21 \\
\hline Twill CF & h-BN, $\mathrm{MoS}_{2}$ & $\begin{array}{l}\text { Sub-micron } \\
\text { size }\end{array}$ & $2,4,6,8$ & $\begin{array}{c}14067 \\
{\left[6 \% \mathrm{MoS}_{2}\right]}\end{array}$ & $\begin{array}{c}1775 \\
{[6 \% \mathrm{~h}-\mathrm{BN}]}\end{array}$ & $\begin{array}{c}0.68 \\
{[8 \% \mathrm{~h}-\mathrm{BN}]}\end{array}$ & $93[4 \% \mathrm{~h}-\mathrm{BN}]$ & Present work \\
\hline
\end{tabular}

**property lesser than neat CEC; CB-Carbon black; G-Graphene.

Table 2. Particulars of reinforcement and matrix materials.

\begin{tabular}{|c|c|c|c|c|}
\hline Properties & Carbon fiber & Epoxy & $\mathrm{MoS}_{2}$ & $\mathrm{~h}-\mathrm{BN}$ \\
\hline Density $\left(\mathrm{kg} \cdot \mathrm{m}^{-3}\right)$ & 1.76 & 1.15 & 5.06 & 2.10 \\
\hline Thermal conductivity & \multirow{2}{*}{498} & \multirow{2}{*}{0.211} & 34 to $98 \dagger$ & 390 to $420 \dagger$ \\
\hline @ Room Temp.(W.m.' $\left.\mathbf{K}^{-1}\right)$ & & & 3.2 to $3.8^{*}$ & 2.5 to $4.8^{*}$ \\
\hline
\end{tabular}

fin-plane direction *cross-plane direction

Table 3. Material combination of the filler loaded CEC and the neat CEC.

\begin{tabular}{ccccc}
\hline Sample designation & Epoxy, Wt.\% $(\mathrm{g})$ & Carbon fabric, Wt.\% $(\mathrm{g})$ & h-BN, Wt.\% $(\mathrm{g})$ & $\mathrm{MoS}_{2}, \mathrm{Wt.} \%(\mathrm{~g})$ \\
\hline CEC & $50(180.00)$ & $50(180.00)$ & - & - \\
\hline 2MSCEC & $48(176.46)$ & $50(180.00)$ & - & $2(3.54)$ \\
\hline 4MSCEC & $46(172.92)$ & $50(180.00)$ & - & $4(7.08)$ \\
\hline 6MSCEC & $44(169.38)$ & $50(180.00)$ & - & $6(10.62)$ \\
\hline 8MSCEC & $42(165.84)$ & $50(180.00)$ & $2(3.52)$ & - \\
\hline 2BNCEC & $48(176.48)$ & $50(180.00)$ & $4(7.05)$ & - \\
\hline 4BNCEC & $46(172.95)$ & $50(180.00)$ & $6(10.55)$ & - \\
\hline 6BNCEC & $44(169.45)$ & $50(180.00)$ & $8(13.82)$ & - \\
\hline 8BNCEC & $42(165.90)$ & $50(180.00)$ & & \\
\hline
\end{tabular}


$4 \mathrm{~mm}$ [10 layers] was achieved. The top and bottom surfaces of the composite were covered with a peel ply to protect from containments. On the top of the peel ply, porous breather fabric cloths were appended to absorb the excess resin. Besides, the breather material acted as a channel for the removal of volatiles during the curing. The entire arrangement was enclosed with a vacuum bag film, which was sealed by a butyl sealant tape. The sealed bag was connected to a vacuum pump through the vacuum valve. After sealing the system, the air leak was tested. The vacuum pressure of $150 \mathrm{~mm}$ of hg was maintained for 20 mins. The pressure difference between the sealed chamber and the outside ambient diffused out the air bubbles. Besides, the vacuum bag method squeezed out the excess resin. The post-curing was completed in a hot air oven at $50^{\circ} \mathrm{C}$ for 2 hrs. during which the residual $\mathrm{OH}$ group present in the epoxy resin formed ether bond and ambient curing for $24 \mathrm{hrs}$. followed it. During crosslinking, the material changed from liquid to glass-like solid via gel. The cured composites were removed from the mold and developed the eight filler loaded CEC and one neat CEC laminate as the control. The fabricated laminate had a fiber volume fraction of approximately $45 \%$ evaluated according to the resin burn-off test.

\subsection{Testing and characterization methods}

The microstructure of the fillers $\mathrm{MoS}_{2}$ and h-BN was studied using a field emission scanning electron microscope
(FESEM) [Made TESCAN-MIRA 3 LMH]. The Raman spectra of the filler loaded CEC and neat CEC materials were obtained using a confocal Raman spectrometer [Made Witec, alpha $300 \mathrm{RA}$ ]. The thermomechanical properties of all the composites were investigated through dynamic mechanical analyzer [Made DMA Q800, TA instrument]. To gain an insight into the thermal stability of the composite, thermogravimetric analysis (TGA) was performed [Made Perkin-Elmer 8000] in an oxygen environment.

\section{Results and Discussion}

\subsection{Morphology of filler}

The images of FESEM of bulk $\mathrm{MoS}_{2}$ powder, as shown in Figure 1, confirm nanosheet morphology and the adjacent sheets are attached to one another to form the stacks. The MoS 2 sheets have a smooth and slightly wrinkled surface found below $809 \mathrm{~nm}$. The analysis of energydispersive X-ray spectroscopy (EDS) [Made QUANTAX 200 BRUKER] of $\mathrm{MoS}_{2}$, as shown in Figure 1, reveals the presence of molybdenum and sulfur. The FESEM micrograph of the filler h-BN, as evident in Figure 2, displays conical morphology and a rod-like structure. The thickness of the h-BN particles varies from 165 to $361 \mathrm{~nm}$ with an average value of $258 \mathrm{~nm}$. The average filler length was found to be $1.13 \mu \mathrm{m}$ as identified by the Image-J software. The EDS
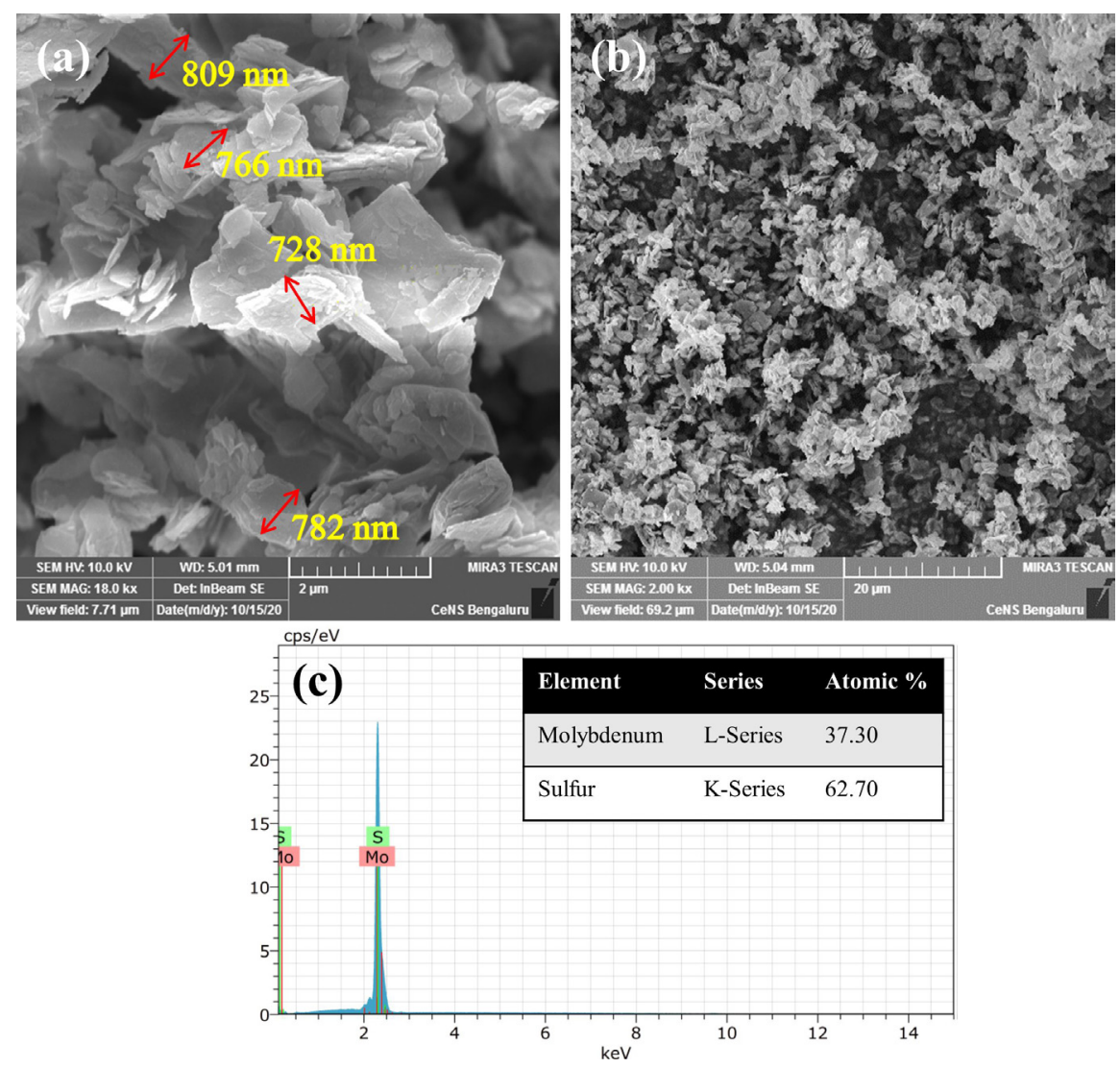

Figure 1. Images of FESEM of pristine $\mathrm{MoS}_{2}$ particles (a) high magnification; (b) low magnification; (c) EDS graph. 
graph of the h-BN, in Figure 2, reveals the presence of boron and nitrogen atoms.

\subsection{Raman spectroscopic analysis}

Raman spectroscopy characterization has proven to be a valuable tool for identification of chemical groups and vibrational/rotational modes of molecular bonds present in the composite. The interaction of incident laser photon signal with the test material produces electric dipole moment and causes vibrations of the molecules which is the basis for
Raman light scattering ${ }^{44}$. The constituents in the composite scatter photons at different proportions due to change in polarizability and exhibit a unique chemical "fingerprint" at a definite frequency. The location of active Raman band based on the group frequency and associated mode of molecular vibration was identified for each element in composites and compared with the standard.

The Raman spectrum of the CEC loaded with the filler and neat CEC is presented in Figure 3. It shows the Raman signal peak at $826 \mathrm{~cm}^{-1}$ resulting from the symmetric stretch
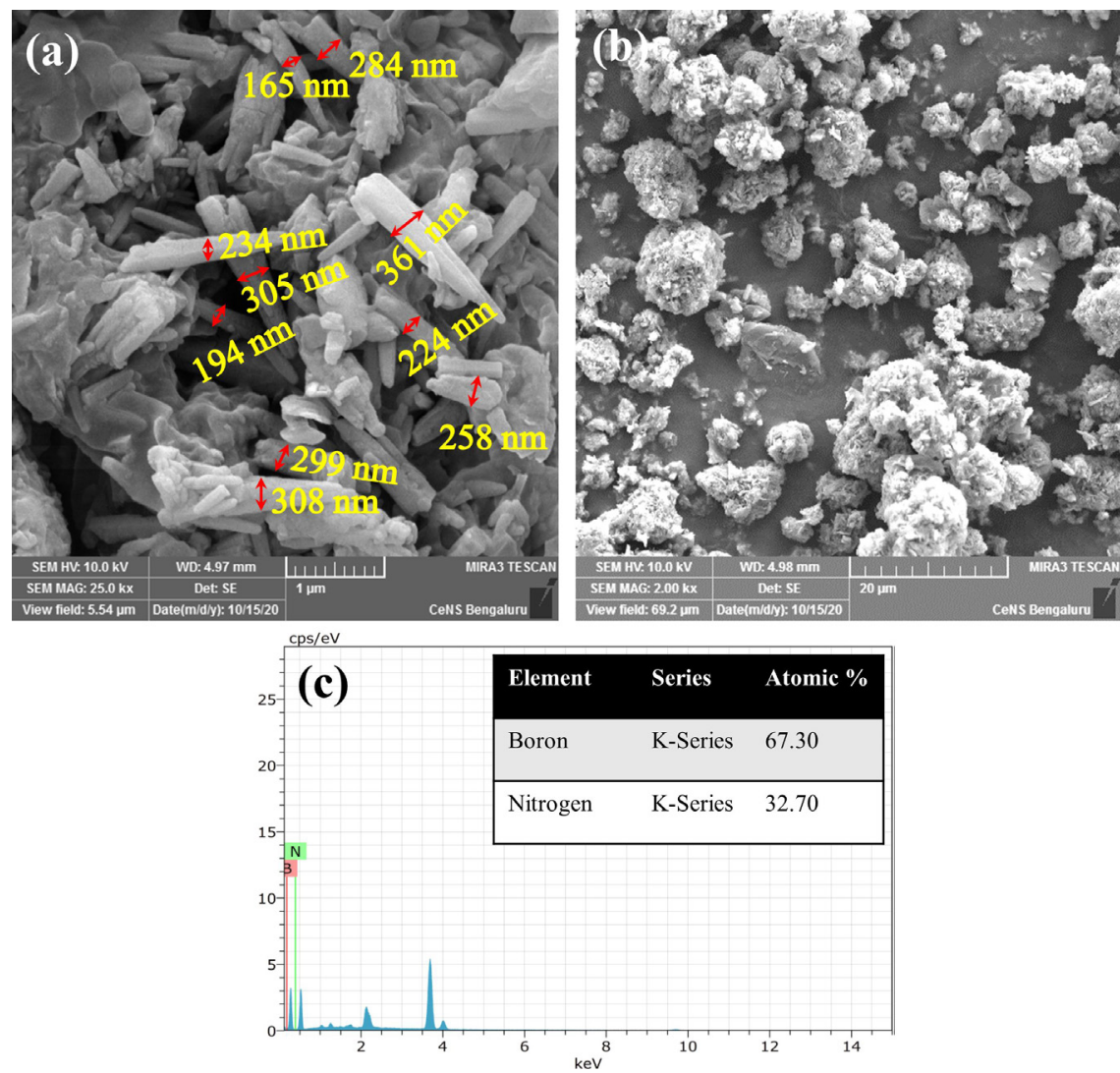

Figure 2. Images of FESEM of pristine h-BN particles (a) high magnification; (b) low magnification; (c) EDS graph.
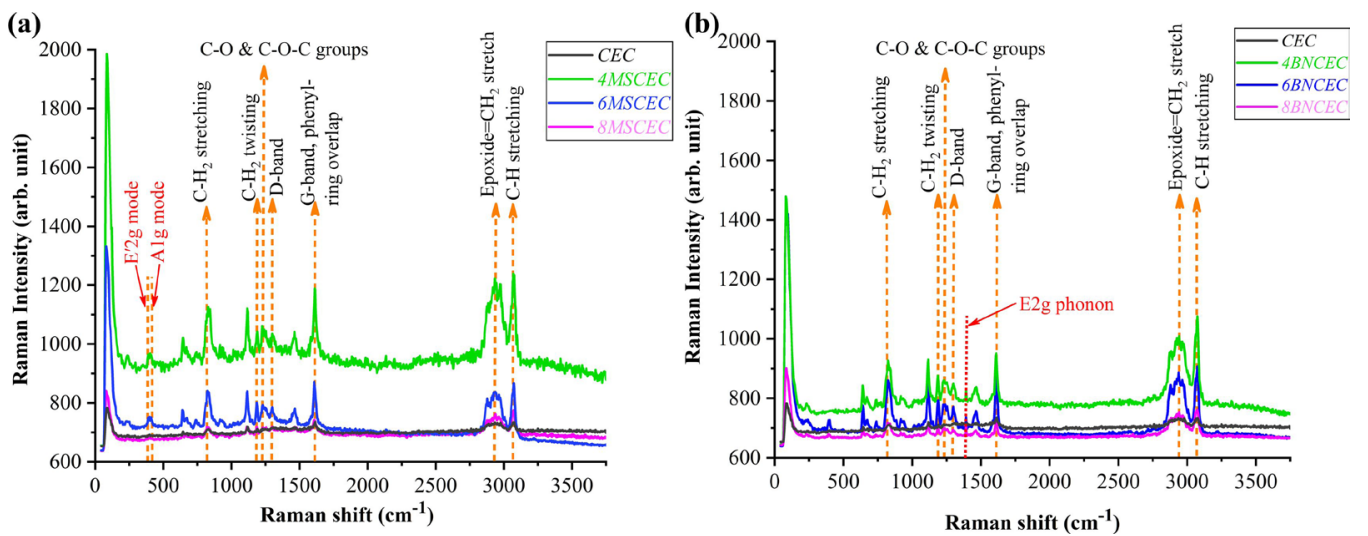

Figure 3. The Raman spectrum (a) the CEC loaded with $\mathrm{MoS}_{2}$ and the neat CEC; (b) the CEC loaded with h-BN and the neat CEC. 
vibration of $\mathrm{CH}_{2}$ group ${ }^{45}$. Similarly, the Raman peak intensity between the wavenumber $1227-1231 \mathrm{~cm}^{-1}$ corresponds to the epoxide group i.e. C-O stretching and C-O-C ether stretching mode of DGBA epoxy, where two bands overlap ${ }^{45,46}$. However, the weaker Raman intensity of epoxide group possibly due to the ring-opening reaction. The peak at $1190 \mathrm{~cm}^{-1}$ in the Raman spectra was related to twisting deformation and vibration of $\mathrm{CH}_{2}$ group $^{45}$. The sharp peak at $1296 \mathrm{~cm}^{-1}$ belonged to the D-band of carbon fiber signifies A1g mode (singly degenerate 1-D vibration) results from the amorphous and disordered carbon structure. The Raman signal peak at $1605 \mathrm{~cm}^{-1}$ was caused due to the G-band of carbon fiber which represents the stretching of hexagonally arranged carbon-carbon lattice structure in E2g mode (doubly degenerate 2-D vibration). The D-band Raman intensity lesser as compared to G-band signifies fewer structural disorder of carbon. The ratio of the D-band to the G-band intensities $\left(\mathrm{I}_{\mathrm{D}} / \mathrm{I}_{\mathrm{G}}\right)$ found to be less than unity for all the composites. In the same way, Jang et al. ${ }^{47}$ reported two distinct Raman bands at the wavenumber 1350 and $1600 \mathrm{~cm}^{-1}$ for Toray 300 carbon fiber. The G-band of carbon fiber may overlap with the phenyl aromatic band stretching between 1604 and $1610 \mathrm{~cm}^{-1}$. The Raman signal peak intensity at $2937 \mathrm{~cm}^{-1}$ associated with the stretch of terminal epoxide $=\mathrm{CH}_{2}$. The low intensity of terminal hydroxy group $\left(3340 \mathrm{~cm}^{-1}\right)$ is due to cure reaction. Asymmetric stretching of C-H group at $3065 \mathrm{~cm}^{-1}$ was due to the DGBA reaction with curing agent ${ }^{46}$.

The Raman spectrum of the CEC loaded with the $\mathrm{MoS}_{2}$ is presented in Figure 3a. Apart from the carbon fiber and epoxy resin characteristic peaks, the $\mathrm{MoS}_{2}$ functional group exhibited a signature peak between the wavenumbers 389 and $411 \mathrm{~cm}^{-1}$ indicative of the in-plane (E'2g) and out-of-plane directions (A1g) intra-layer vibration. The $E^{\prime} 2 \mathrm{~g}$ peak appeared as a result of internal vibration of sulfur atoms relative to the molybdenum layer, A1g peak related to out-of-layer vibration of sulfur atoms ${ }^{48}$. Likewise, Frey et al. ${ }^{48}$ observed Raman peaks at 383 and $408 \mathrm{~cm}^{-1}$ for $\mathrm{MoS}_{2}$ particles when considering laser excitation wavelength of $500 \mathrm{~nm}$ i.e. different from the wavelength of the present study $(532 \mathrm{~nm})$. This difference in excitation wavelength lead to a slight variation in the location of Raman peak intensity compared to the published literature since the incident laser wavelength has a notable effect on the dipole moment, in turn on Raman active mode ${ }^{49}$. The composites loaded with 4 and $6 \mathrm{Wt} . \%$ $\mathrm{MoS}_{2}$ showed a larger $\mathrm{MoS}_{2}$ characteristic peak intensity. Also, the two Raman peaks (E'2g and A1g) in $\mathrm{MoS}_{2}$ loaded CEC appeared at a nearly constant wavenumber gap $\left(26 \mathrm{~cm}^{-1}\right)$ signified several layers of $\mathrm{MoS}_{2}$ filler present in the composite. Figure 3 b displays the Raman spectrum associated with the h-BN loaded CEC series. It reveals the Raman scattering near $1370 \mathrm{~cm}^{-1}$ wavenumber and infers the $\mathrm{E} 2 \mathrm{~g}$ phonon band due to the presence of a functional group of h-BN. In the same way, the researchers Nemanich et al. ${ }^{50}$ reported Raman peak for h-BN at wavenumber $1366 \mathrm{~cm}^{-1}$. The Raman spectra in both types of hybrid filler loaded composites containing a filler with 4, $6 \mathrm{Wt}$.\% exhibited a larger G-band intensity. Hence, it confirms improved matrix to fiber stress transfer. The shorter bond length h-BN (1.45 $\AA$ ) shows the Raman characteristic peak at a higher wavenumber than the $\mathrm{MoS}_{2}(2.43 \AA)$. The Raman spectra peak at low frequency $\left(<100 \mathrm{~cm}^{-1}\right)$ is due to a highly reflective sample and therefore the intensity is too strong for the notch filter.

\subsection{Dynamic mechanical analysis}

The dynamic mechanical analysis (DMA) provides information on the softening temperature, the maximum operative temperature, the change in stiffness and the damping properties of composites due to the synergetic effect of cyclic bending load and temperature rise ${ }^{51}$.

The dynamic properties were measured as per ASTM D $7028-07^{51}$ at a loading frequency $1 \mathrm{~Hz}$, heating rate $5^{\circ} \mathrm{C}$. $\mathrm{min}^{-1}$ by varying the temperature from ambient to $200^{\circ} \mathrm{C}$. The dimension of the test sample was $57 \mathrm{~mm} \times 13 \mathrm{~mm} \times$ $4 \mathrm{~mm}$. The cyclic deformation of amplitude $20 \mu \mathrm{m}$ was applied at the center of the test sample with their ends being clamped (dual cantilever beam flexural setup). The E', E", and $\tan \delta$ were the responses determined as a function of temperature. The typical variation of elastic modulus with temperature is presented in Figure 4.

\subsubsection{Effect of filler on storage modulus $\left(E^{\prime}\right)$}

The strength of the intermolecular forces, the packing, and the mobility of the polymer chains decide the E'. As the temperature increased, the composite experiences a relaxation mainly due to the cooperative movement of polymer chain segments. The easier polymer chain motion and energy dissipation in the relaxation process reduce the effective stress transfer between the constituents, which, in turn, lower the stiffness and the $\mathrm{E}^{\prime}$. The $\mathrm{E}^{\prime}$ of the material drops by more than one order at the $\mathrm{Tg}^{52}$. The $\mathrm{E}^{\prime}$ variation with the temperature at different filler concentrations is presented in Figure 5. Both the h-BN and $\mathrm{MoS}_{2}$ have positive effects on the $\mathrm{E}^{\prime}$ in glassy as well as rubbery regions up to $6 \mathrm{Wt} . \%$. The $\mathrm{E}^{\prime}$ was greatly affected by filler concentration below Tg. A similar effect was elucidated by Loos et al. ${ }^{34}$ for CNTs loaded epoxy composite. The filler loaded epoxy resin forms a polymer-filler continuous network and modifies the epoxy matrix-carbon fiber interaction. The $\mathrm{MoS}_{2}$ as well as h-BN fillers possibly occupied the free matrix volume and lowered the segmental mobility of the polymer chains due to chemical crosslinks. The maximum $\mathrm{E}^{\prime}$ of $14067 \mathrm{MPa}$ was noticed for $6 \mathrm{MSCEC}$ at $35^{\circ} \mathrm{C}$ and it represents $70 \%$

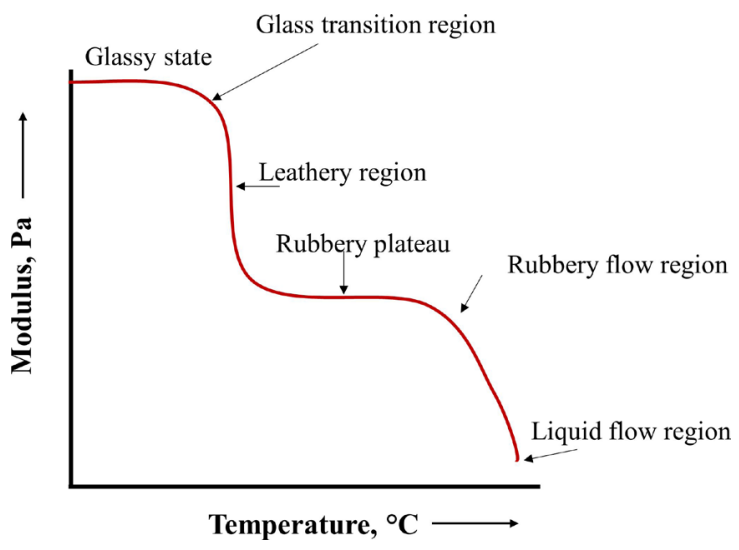

Figure 4. An ideal graph of elastic modulus versus temperature of FRP composite. 
(a)

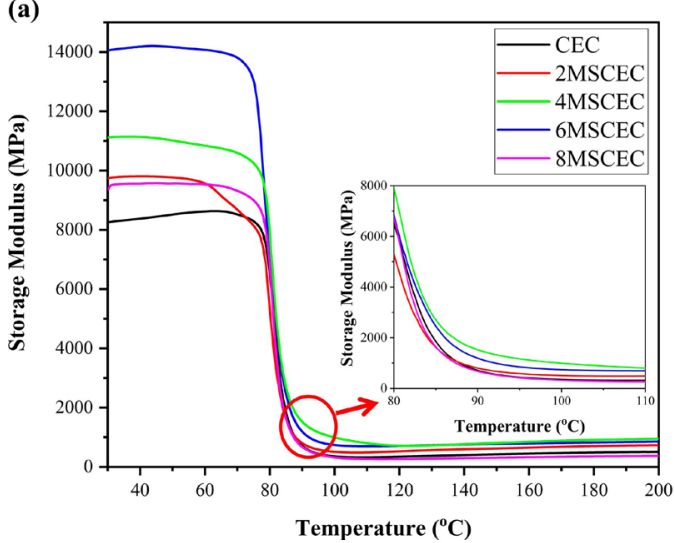

(b)

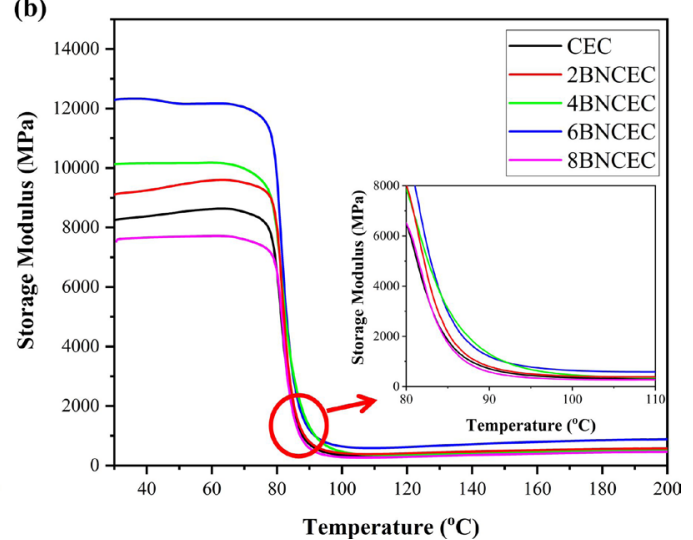

Figure 5. The plot of storage modulus versus temperature (a) the CEC loaded with $\mathrm{MoS}_{2}$ and the neat CEC; (b) the CEC loaded with $\mathrm{h}-\mathrm{BN}$ and the neat CEC.

larger than the neat CEC having a value of $8256 \mathrm{MPa}$. The $\mathrm{MoS}_{2}$ at $6 \mathrm{Wt} . \%$ perhaps creates a stiffer $\mathrm{MoS}_{2}$ /epoxy chain network, and higher crosslinks between the surfaces of the fibers/fillers. Hence, a greater level of stress transfer was possible and improved E'. A similar effect reported by Azimpour-Shishevan et al. ${ }^{53}$ for soft fillers (CNTs/graphene) strengthened CEC. The next highest $\mathrm{E}^{\prime}$ of $12295 \mathrm{MPa}$ was observed for 6BNCEC. However, the composites reinforced beyond $6 \mathrm{Wt} . \%$ filler have the lower $\mathrm{E}^{\prime}$ signifying the detrimental effect of filler at the higher concentration causing stress accumulation. The lower $\mathrm{E}^{\prime}$ of the composite is also associated with the slip of filler in the epoxy matrix under dynamic loading.

The various scholars incorporated filler such as $\mathrm{B}_{4} \mathrm{C}^{18}$, $\mathrm{SiC}^{30}, \mathrm{SiO}_{2}{ }^{19}$, clay $^{20,21,33}$, graphene platelets ${ }^{22,23}, \mathrm{GO}^{31}$ and concluded that their presence favorable for improving $\mathrm{E}^{\prime}$ of CEC. Likewise, the previous studies showed that $\mathrm{E}^{\prime}$ of epoxy was improved by the inclusion of $\mathrm{h}-\mathrm{BN}^{26}$, graphene ${ }^{24}$, and $\mathrm{GO}^{32}$ filler. However, very few research works available describing the effect of $\mathrm{MoS}_{2}$, h-BN filler on $\mathrm{E}^{\prime}$ of the CEC that too available only in the higher filler $\mathrm{Wt} . \%$ and not in the wider range. In the present study $\mathrm{E}^{\prime}$ improved up to $70 \%$ for $6 \mathrm{Wt} . \% \mathrm{MoS}_{2}$ reinforced CEC and $49 \%$ for $6 \mathrm{Wt} . \%$ h-BN reinforced CEC.

Based on the obtained result, the $\mathrm{E}^{\prime}$ of $\mathrm{MoS}_{2}$ composite series below $\mathrm{Tg}$ from the highest to the lowest level is in the order $-6 \mathrm{MSCEC}>4 \mathrm{MSCEC}>2 \mathrm{MSCEC}>8 \mathrm{MSCEC}$ $>$ CEC. The $\mathrm{E}^{\prime}$ of $\mathrm{BN}$ composite series below $\mathrm{Tg}$ from the highest to the lowest level is as follows - 6BNCEC > $4 \mathrm{BNCEC}>2 \mathrm{BNCEC}>\mathrm{CEC}>8 \mathrm{BNCEC}$. The glassy region (developed temperature $<\mathrm{Tg}$ ) is characterized by high stiffness, $\mathrm{E}^{\prime}$ and restricted molecular chain motion. The $\mathrm{E}^{\prime}$ in all the composites above $\mathrm{Tg}$ (rubbery region) becomes low since the resin matrix loses its stability ${ }^{54}$. Hence, the composite can store more energy at a temperature below $\operatorname{Tg}$ (glassy state).

\subsubsection{Effect of filler on loss modulus ( $\left.E^{\prime \prime}\right)$}

When the cyclic load is applied to the composite, the filler along with fiber reinforcement tries to hold the laminate in place. However, certain activation energy is essential to deform the sample and overcome the barrier for molecular motions ${ }^{55}$. During this process, some amount of energy is dissipated. The $E^{\prime \prime}$ is the measure of the internal heat energy dissipated from the composites related to the internal friction of filler/fiber-matrix caused by the phase transformation under dynamic loading. The viscoelastic lag between stress and strain is denoted by $\mathrm{E}^{\prime \prime}$. The variation of $\mathrm{E}^{\prime \prime}$ with temperature is indicated in Figure 6. The $\mathrm{E}^{\prime \prime}$ attains a peak value at the $\mathrm{Tg}$ where the onset of segmental motion of epoxy polymer chains occurs. The h-BN fillers have excellent thermal conductivity (Table 2) and therefore it facilitates in the larger improvement of the composite thermal conductivity than the $\mathrm{MoS}_{2}$. Hence, the h-BN reinforced CEC enhances heat dissipation leading to the higher $\mathrm{E}^{\prime \prime}$. The enhancement of $\mathrm{E}^{\prime \prime}$ was observed up to $6 \mathrm{Wt} . \% \mathrm{~h}-\mathrm{BN}$ (33\% improved) and $4 \mathrm{Wt} . \% \mathrm{MoS}_{2}$ reinforced CEC (9\% improved), and later it was reduced compared to neat $\mathrm{CEC}$. This observation agree with the work of Apsarraj et al. ${ }^{42}$ who reported a declining trend for $\mathrm{E}^{\prime \prime}$ at 5 and $10 \mathrm{Wt} . \% \mathrm{MoS}_{2}$ (size: $25 \mu \mathrm{m}$ ) reinforced unidirectional CEC. The maximum E" of $1775 \mathrm{MPa}$ was noticed for $6 \mathrm{BNCEC}$ at $88^{\circ} \mathrm{C}(\mathrm{Tg})$ and related the broadening of $E^{\prime \prime}$ peak to the inhibition of relaxation process. The next highest $\mathrm{E}^{\prime \prime}$ of $1530 \mathrm{MPa}$ was observed for 4BNCEC at $92^{\circ} \mathrm{C}(\mathrm{Tg})$. The higher $\mathrm{E}^{\prime \prime}$ conveys better filler-epoxy matrix interaction and strong internal friction. Beyond the respective $\mathrm{Tg}$ it reduced the $\mathrm{E}^{\prime \prime}$.

The earlier research studies depicted improvement in $\mathrm{E}^{\prime \prime}$ of $\mathrm{CEC}$ with the inclusion of $\mathrm{B}_{4} \mathrm{C}^{18}, \mathrm{SiC}^{30}, \mathrm{SiO}_{2}{ }^{19}$, clay ${ }^{20}$, graphene $\mathrm{e}^{22,23,33}$, and $\mathrm{GO}^{31}$.

\subsubsection{Effect of filler on loss factor}

We evaluated the tangent of the phase angle $(\delta)$ based on the ratio of the $E^{\prime \prime}$ to $E^{\prime}$. It signified balance between the elastic and the viscous phases of polymer composites ${ }^{56}$. The $\tan \delta$ indicated how good a material dissipated energy under a cyclic load, which depends on the bond rotation and intermolecular friction. The peak position of loss factor curve illustrated the high damping owing to the chain motion ${ }^{53}$.

The graphical variation of the $\tan \delta$ with temperature for various composites is shown in Figure 7. When the temperature was below $\mathrm{Tg}$ the molecules in the composite packed closely and the chain segments in a frozen state causing low $\tan \delta$. The $\tan \delta$ reached the maximum at $\mathrm{Tg}$ 

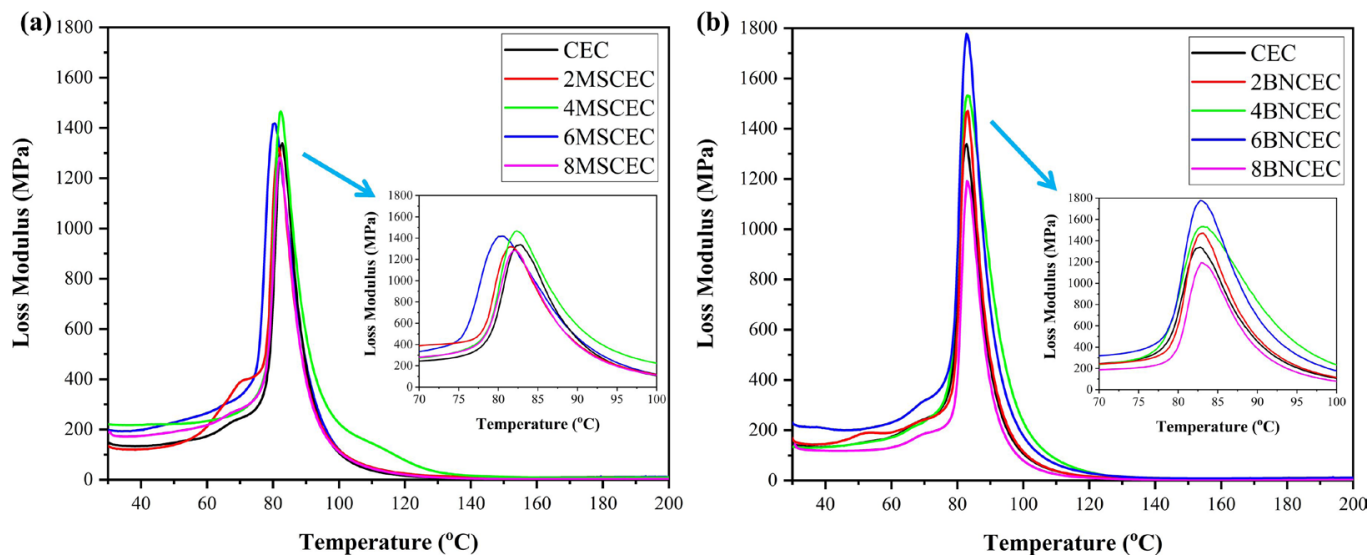

Figure 6. The plot of loss modulus versus temperature (a) the $\mathrm{CEC}$ loaded with $\mathrm{MoS}_{2}$ and the neat $\mathrm{CEC}$; (b) the CEC loaded with h-BN and the neat CEC.
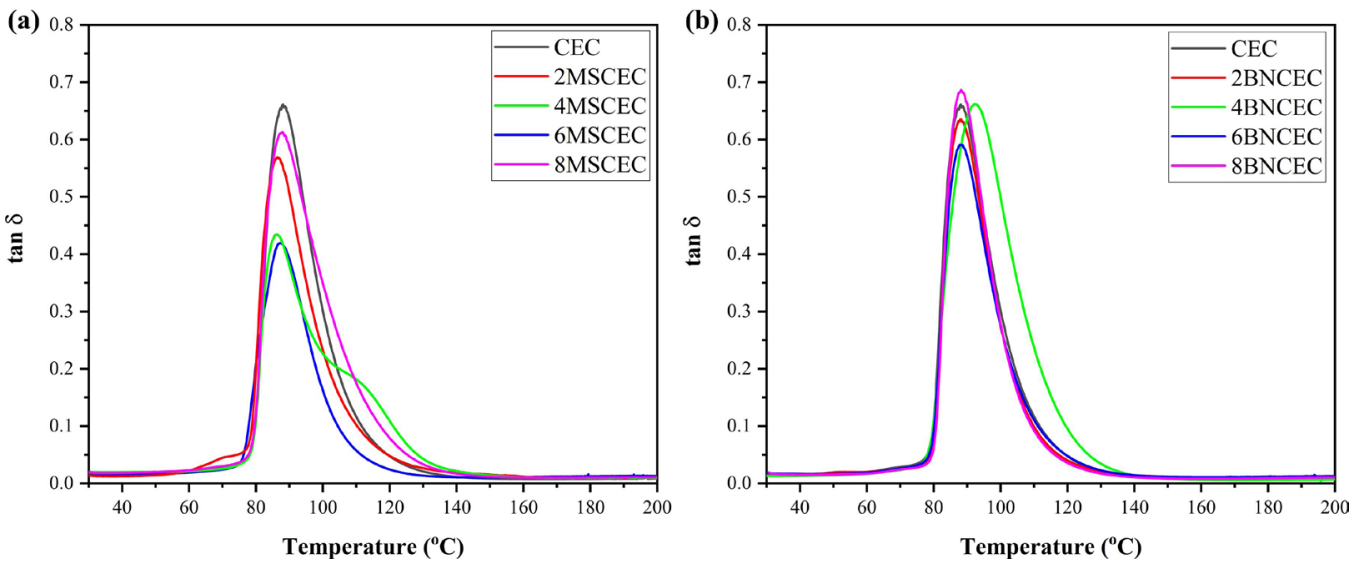

Figure 7. The plot of $\tan \delta$ versus temperature (a) the CEC loaded with $\mathrm{MoS}_{2}$ and the neat CEC; (b) the CEC loaded with h-BN and the neat CEC.

where the resin molecules attained high mobility ${ }^{56}$. At the transition regime, the maximum molecular chain participated in the micro-Brownian movement (conjunctive diffusion), and hence energy dissipation causes maximal damping ${ }^{57}$. Beyond Tg, the $\tan \delta$ started decreasing. With the increase in temperature, the happening of filler-matrix interface slippage might also dissipate the energy ${ }^{8,58}$. The low $\tan \delta$ recorded for $6 \mathrm{MSCEC}$ sample $(36 \% \downarrow)$ implied a more constrained region due to the larger filler contact area with the epoxy, indicated effective filler dispersion in the epoxy networks that stiffen the composites. Apsarraj et al. ${ }^{42}$ as well reported tan $\delta$ decrement for 5 and $10 \mathrm{Wt} . \% \mathrm{MoS}_{2}$ reinforced unidirectional $\mathrm{CEC}$. In the same way, $\tan \delta$ peak height of h-BN loaded CEC lowered until $6 \mathrm{Wt} . \%(11 \% \downarrow)$ due to stiffness enhancement and mobility restriction of the h-BN blend epoxy. A similar effect confirmed by Joy et al. ${ }^{26}$ for nano h-BN loaded epoxy resin. Among the filler loaded composites, the maximum tan $\delta$ of $0.687(\mathrm{~h}-\mathrm{BN})$ and $0.611\left(\mathrm{MoS}_{2}\right)$ were observed for the filler loading of $8 \mathrm{Wt} . \%$ at $\mathrm{Tg}$.

Several scholars revealed that filler such as $\mathrm{SiC}^{30}$, $\mathrm{SiO}_{2}{ }^{19}$ lowered tan $\delta$ whereas $\mathrm{B}_{4} \mathrm{C}^{18}, \mathrm{GNP}^{23}, \mathrm{GO}^{31}$ increased $\tan \delta$ of CEC. In addition to that, some studies showed that clay $^{20,21}$, graphene ${ }^{22}$ increased tan $\delta$ of CEC but lowered tan $\delta$ when it was added to the epoxy ${ }^{21,24}$. Hence, increased $\tan \delta$ of filler loaded CEC might be due to the inherent damping properties of carbon fiber which reduced intermolecular friction and improved energy dissipation.

\subsubsection{Effect of filler on $\mathrm{Tg}$}

The heated composite material transformed from the glassy to rubbery state attributable to the mobility change of polymer chains at a temperature known as $\mathrm{Tg}^{52}$. The temperature that corresponded to the peak of $\tan \delta$ curve was considered the Tg. Below the Tg, the polymer chains were locked as they do not have sufficient energy to cause structure transformation. When the temperature exceeds $\mathrm{Tg}$, the polymer molecules could slide each other and the material turned flexible ${ }^{58}$. The Tg obtained depended on segmental mobility of the polymer chains and it, in turn, depended on the chain stiffness, steric hindrance, and availability of space for the molecular motion. The addition of the fillers $\mathrm{MoS}_{2}{ }^{27}$ and h-BN ${ }^{26}$ affected the mobility of the epoxy chains and varied the Tg. Besides, the Tg was also affected by the crosslinking density, the dispersion of filler and its interaction with the epoxy resin ${ }^{31}$. With the $4 \mathrm{Wt} . \% \mathrm{~h}-\mathrm{BN}$ incorporation in the $\mathrm{CEC}$, the maximum $\mathrm{Tg}$ was attained 
i.e. an increase from 88.09 to $92.48^{\circ} \mathrm{C}$. It was attributed to the increased chain rigidity and stronger fiber-polymer-filler interactions due to the improved filler dispersion. Therefore, the greater resistance to the motion of polymer molecules demanded more heat energy. Joy et al. ${ }^{26}$ also reported $\mathrm{Tg}$ improvement for h-BN loaded epoxy. However, when the h-BN concentration exceeded $4 \mathrm{Wt} \%$ the easy sliding between the h-BN particles became prominent, likely reduced the crosslinking points, and lowered the $\mathrm{Tg}$. In contrast, the $\mathrm{MoS}_{2}$ filled CEC slightly lowered the Tg which might be due to anisotropy of thin wrinkled $\mathrm{MoS}_{2}$, barrier effect and tendency to lose brittleness with $\mathrm{MoS}_{2}$. It was recognized from the shift in the $\tan \delta$ peak towards the lower temperature. The $\mathrm{Tg}$ reduction up to $1.74^{\circ} \mathrm{C}$ is noticed for $2 \mathrm{MSCEC}$. A similar reduction of $\mathrm{Tg}$ was found in the literature for soft filler (graphene) loaded $\mathrm{CEC}^{22}$.

Based on the DMA, the degree of crosslinking was evaluated according to the Equation $1^{59}$.

Crosslink density $=\frac{\text { E'r }}{\mathrm{RT}}$

Where, $\mathrm{E}_{\mathrm{r}}^{\prime}=$ Storage modulus $(\mathrm{MPa})$ measured at the rubbery region, $\mathrm{R}=$ Universal gas constant $\left(8.314 \mathrm{~J} \cdot \mathrm{K}^{-1} \cdot \mathrm{mol}^{-1}\right)$, $\mathrm{T}=$ temperature corresponding to the $\mathrm{E}^{\prime} \mathrm{r}\left(381^{\circ} \mathrm{K}\right)$.

The crosslink density has been expressed in the moles of elastically effective network chains per unit volume. The higher crosslink density witnessed for 4MSCEC and 6MSCEC in the order 0.262 and $0.221 \mathrm{~mol} . \mathrm{cm}^{-3}$, respectively. In both the types of composites, filler concentration of $8 \mathrm{Wt} . \%$ caused a low crosslink density due to localized agglomeration which possibly lowered the filler entry into the inter chain spacing of polymer and decreased the polymer-filler crosslink. The result of the DMA is given in Table 4.

\subsection{Thermogravimetric analysis: ambient condition}

The TGA provides information regarding the heat resistance and decomposition behavior of the polymeric material ${ }^{60}$. The TGA under the oxygen atmosphere guarantees the complete decomposition of both the epoxy matrix and carbon fiber. The test comprises recording the change in weight of the composite once it was subjected to an increase in temperature. The test involves two-stage heating. Initially, the composite samples $(5-10 \mathrm{mg})$ were heated from 50 to $600^{\circ} \mathrm{C}$ in a hermetic aluminum crucible at $20^{\circ} \mathrm{C} \cdot \mathrm{min}^{-1}$ and held at $600^{\circ} \mathrm{C}$ for $1 \mathrm{~min}$. Secondly, the sample was heated to a temperature of $900^{\circ} \mathrm{C}$ at $20^{\circ} \mathrm{C} \cdot \mathrm{min}^{-1}$, and held at $900^{\circ} \mathrm{C}$ for $10 \mathrm{~min}$.

The characteristics of the thermally stable material are the higher softening temperatures, the more residual mass, and the minimal deviations in the physical or chemical properties $^{61}$. The thermograms of different composite samples are presented in Figure 8. At a very low temperature, the
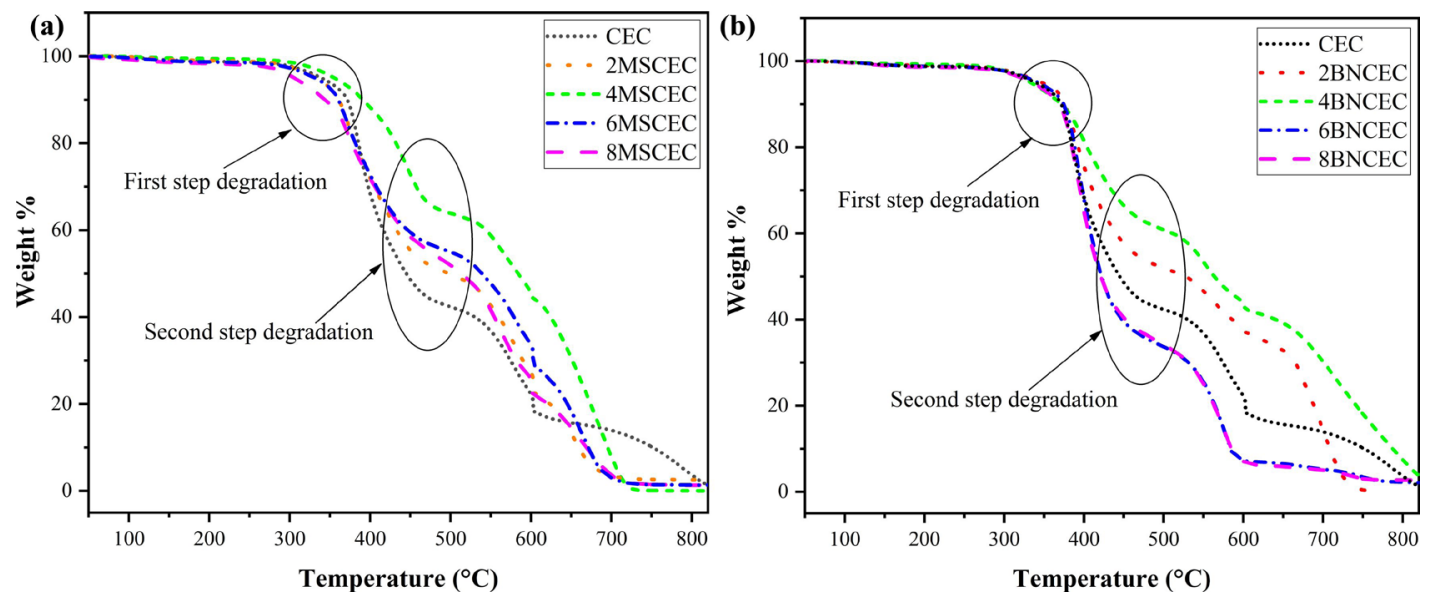

Figure 8. Thermograms of composites (a) the CEC loaded with $\mathrm{MoS}_{2}$ and the neat CEC; (b) the CEC loaded with h-BN and the neat CEC.

Table 4. Dynamic properties of the filler loaded CEC and the neat CEC.

\begin{tabular}{ccccccc}
\hline $\begin{array}{c}\text { Sample } \\
\text { designation }\end{array}$ & $\begin{array}{c}\mathrm{E}^{\prime} @ 35^{\circ} \mathrm{C} \\
(\mathrm{MPa})\end{array}$ & $\begin{array}{c}\mathrm{E}^{\prime} @\left(108^{\circ} \mathrm{C}\right. \\
(\mathrm{MPa})\end{array}$ & Max E" $(\mathrm{MPa})$ & $\operatorname{Max} \tan \delta$ & $\operatorname{Tg}\left({ }^{\circ} \mathrm{C}\right)$ & $\begin{array}{c}\text { Crosslink density } \\
\left(\mathrm{mol} . \mathrm{cm}^{-3}\right)\end{array}$ \\
\hline CEC & 8256 & 328.240 & 1335.290 & 0.661 & 88.097 & 0.104 \\
\hline 2MSCEC & 9759 & 488.960 & 1321.731 & 0.569 & 86.358 & 0.154 \\
\hline 4MSCEC & 11126 & 828.520 & 1446.890 & 0.434 & 86.469 & 0.262 \\
\hline 6MSCEC & 14067 & 699.490 & 1416.308 & 0.419 & 87.173 & 0.221 \\
\hline 8MSCEC & 9472 & 260.330 & 1284.530 & 0.611 & 87.484 & 0.082 \\
\hline 2BNCEC & 9127 & 391.620 & 1467.264 & 0.634 & 88.215 & 0.124 \\
\hline 4BNCEC & 10139 & 348.610 & 1530.957 & 0.659 & 92.481 & 0.110 \\
\hline 6BNCEC & 12295 & 595.360 & 1775.042 & 0.590 & 88.137 & 0.188 \\
\hline 8BNCEC & 7556 & 276.170 & 1194.144 & 0.687 & 88.064 & 0.087 \\
\hline
\end{tabular}


Table 5. Temperature at different weight losses of various composites.

\begin{tabular}{cccc}
\hline Sample designation & Temp. $\left({ }^{\circ} \mathrm{C}\right) @ 25 \%$ Wt. loss & Temp. $\left({ }^{\circ} \mathrm{C}\right) @ 50 \%$ Wt. loss & Temp. $\left({ }^{\circ} \mathrm{C}\right) @ 75 \%$ Wt. loss \\
\hline CEC & 390.69 & 445.41 & 590.79 \\
\hline 2MSCEC & 391.97 & 500.32 & 602.46 \\
\hline 4MSCEC & 444.14 & 584.22 & 663.02 \\
\hline 6MSCEC & 393.25 & 539.35 & 626.90 \\
\hline 8MSCEC & 389.60 & 514.36 & 600.46 \\
\hline 2BNCEC & 401.60 & 530.26 & 677.47 \\
\hline 4BNCEC & 418.65 & 565.12 & 721.61 \\
\hline 6BNCEC & 393.32 & 422.68 & 551.82 \\
\hline 8BNCEC & 390.31 & 421.66 & 550.57 \\
\hline
\end{tabular}

molecular chains are fixed, holding the filler/fiber with the matrix. However, the chains move freely at an elevated temperature and the interaction between the matrix and the filler/fiber becomes weak. This causes a reduction in the thermal stability. In the first stage, decomposition is related to the evaporation of moisture content and volatilization of the epoxy matrix (degradation because of chain scission $)^{62}$ starts near the temperature $260^{\circ} \mathrm{C}$. Similarly, at this temperature there can be a small reduction in the content of oxygen present at the carbon fiber surface. Further, the combustion of residual carbon of epoxy resin occurs between 420 to $600^{\circ} \mathrm{C}^{63}$ besides carbon fiber experiences oxidation and turns into $\mathrm{CO}_{2}$ vapor $^{64}$. The decomposition temperatures of different composites evaluated at 25,50 , and $75 \%$ weight loss are displayed in Table 5 . The thermal stability of both the h-BN reinforced CEC and $\mathrm{MoS}_{2}$ reinforced CEC are comparable. The decomposition temperature is shifted slightly to a higher temperature as a solid-lubricant filler is reinforced to the epoxy resin. Among all, 4MSCEC and 4BNCEC materials need the higher heat energy for the complete thermal decomposition and it is thermally stable. This improvement in the thermal stability is identified by the increase in decomposition temperature attributed to rigid $\mathrm{MoS}_{2}$ filler that restrains the mobility of the epoxy chains and barrier effect of $\mathrm{MoS}_{2}$ restricts the osmosis of heat consequently delay the oxidation (slow down heat and mass transfer $)^{65}$ and release of pyrolysis gas. Moreover, $\mathrm{MoS}_{2}$ oxidizes to molybdenum trioxide $\left(\mathrm{MoO}_{3}\right)$ that potentially suppresses the smoke ${ }^{65}$. Similarly, h-BN filler also impedes the escape of decomposition products and delayed the evaporation of volatile matter promoting thermal stability.

\section{Conclusions}

We investigated the dynamic mechanical properties and the thermal stability of carbon fabric reinforced epoxy with fillers - h-BN and $\mathrm{MoS}_{2}$ and arrived at the following conclusions:

- The local filler networks at $6 \mathrm{Wt} . \%\left(\mathrm{MoS}_{2} / \mathrm{h}-\mathrm{BN}\right)$ in the carbon fabric-epoxy composite transferred the applied external load and improved the stiffness and the $\mathrm{E}^{\prime}$ of the composite. Particularly, $\mathrm{MoS}_{2}$ reinforced CEC improved $\mathrm{E}^{\prime}$ up to $70 \%$ as it promoted stiffening and crosslink density.

- The internal heat energy dissipation was large for the maximum loss modulus witnessed in the 6BNCEC (improved by 33\%) at the transition state temperature. The larger energy dissipation indicated more resistance towards the viscoelastic deformation of epoxy matrix due to better filler distribution in the matrix. Although, the height of $\tan \delta$ peak lowered with solid lubricant filler $\left(\mathrm{MoS}_{2}\right.$ as well as h-BN) loaded CEC, it did not reduce much like hard filler loaded composite in the published literature.

- The 4MSCEC and the 4BNCEC showed superior thermal stability due to better filler-epoxy interaction with a low mass loss at an elevated temperature. The smoke suppressing characteristics and rigid filler (restrains the epoxy chains mobility) responsible for the delay of thermal decomposition.

- The filler addition above the critical limit (6 Wt.\%) reduced the adhesion of the reinforcement-matrix due to particle-particle interface and lowered the DMA properties.

- The Raman spectrum of the filler reinforced CEC confirmed the presence of filler by showing its Raman signature at the wavenumber 389 and 411 $\mathrm{cm}^{-1}$ for $\mathrm{MoS}_{2}$ while $1370 \mathrm{~cm}^{-1}$ for h-BN apart from the carbon fiber and epoxy resin. The larger G-band Raman intensity of 4 and $6 \mathrm{Wt} \% \%$ filler loaded CEC confirmed the improved matrix to fiber stress transfer via the filler.

- From the present investigation, the optimum soft filler (h-BN/MoS $)_{2}$ addition in CEC caused noteworthy improvement of storage modulus, loss modulus, crosslink density, and thermal stability. Therefore, composites derived from such low-cost and abundantly available solid lubricant filler are a good choice for elevated temperature environments and are recommended for future studies.

\section{Acknowledgments}

The authors are grateful to Dr. Siddaramaiah, HOD, Polymer Science \& Technology, SJCE, Mysuru for providing the DMA test facility. The authors are thankful to Mr. Sridhar T, Mr. Manohar R, Mr. Sandeep D for assisting to carry out tests.

\section{References}

1. Zhang J, Chevali VS, Wang H, Wang CH. Current status of carbon fibre and carbon fibre composites recycling. Compos, 
Part B Eng. 2020;193:108053. http://dx.doi.org/10.1016/j. compositesb.2020.108053.

2. Fathi B, Esfandeh M, Soltani AK, Amraei IA. Effect of fiber acid treatment on the dynamic mechanical properties of unsaturated polyester/carbon fiber unidirectional composites. Polym Plast Technol Eng. 2011;50(6):564-7. http://dx.doi.org/10.1080/036 02559.2010 .543243 .

3. Abdelal NR, Al-Saleh MH, Irshidat MR. Utilizing vacuum bagging process to prepare carbon fiber/CNT-modified-epoxy composites with improved mechanical properties. Polym Plast Technol Eng. 2018;57(3):175-84. http://dx.doi.org/10.1080/0 3602559.2017.1315644.

4. Dai Z, Zhang B, Shi F, Li M, Zhang Z, Gu Y. Effect of heat treatment on carbon fiber surface properties and fibers/epoxy interfacial adhesion. Appl Surf Sci. 2011;257(20):8457-61. http://dx.doi.org/10.1016/j.apsusc.2011.04.129.

5. Rana S, Alagirusamy R, Joshi M. Mechanical behavior of carbon nanofibre-reinforced epoxy composites. J Appl Polym Sci. 2010;118(4):2276-83.

6. Thipperudrappa S, Ullal Kini A, Hiremath A. Influence of zinc oxide nanoparticles on the mechanical and thermal responses of glass fiber-reinforced epoxy nanocomposites. Polym Compos. 2020;41(1):174-81. http://dx.doi.org/10.1002/pc.25357.

7. Mazumdar S. Composites manufacturing: materials, product, and process engineering. Boca Raton: CRC Press; 2001.

8. Chung DDL. Composite materials: functional materials for modern technologies. In: Derby B, editor. Engineering materials and processes. London: Springer; 2003.

9. Joy J, Winkler K, Joseph K, Anas S, Thomas S. Epoxy/methyl methacrylate acrylonitrile butadiene styrene (MABS) copolymer blends: reaction-induced viscoelastic phase separation, morphology development and mechanical properties. New J Chem. 2019;43(23):9216-25. http://dx.doi.org/10.1039/ C8NJ05653F.

10. Rahmani H, Najafi SHM, Saffarzadeh-Matin S, Ashori A. Mechanical properties of carbon fiber/epoxy composites: effects of number of plies, fiber contents, and angle-ply layers. Polym Eng Sci. 2014;54(11):2676-82. http://dx.doi.org/10.1002/ pen. 23820 .

11. Phadnis VA, Makhdum F, Roy A, Silberschmidt VV. Drilling in carbon/epoxy composites: experimental investigations and finite element implementation. Compos, Part AAppl Sci Manuf. 2013;47(1):41-51.

12. Xu J, Li C, Chen M, El Mansori M, Ren F. An investigation of drilling high-strength CFRP composites using specialized drills. Int J Adv Manuf Technol. 2019;103(9-12):3425-42. http://dx.doi.org/10.1007/s00170-019-03753-8.

13. Gaugel S, Sripathy P, Haeger A, Meinhard D, Bernthaler T, Lissek F, et al. A comparative study on tool wear and laminate damage in drilling of carbon-fiber reinforced polymers (CFRP). Compos Struct. 2016;155:173-83. http://dx.doi.org/10.1016/j. compstruct.2016.08.004.

14. Buragohain MK. Composite structures: design, mechanics, analysis, manufacturing and testing. Boca Raton: CRC Press; 2017.

15. Startsev OV, Vapirov YM, Lebedev MP, Kychkin AK. Comparison of glass-transition temperatures for epoxy polymers obtained by methods of thermal analysis. Mech Compos Mater. 2020;56(2):227-40. http://dx.doi.org/10.1007/s11029-02009875-5.

16. Adams D. Glass transition temperature testing of composites. Composites World; 2018.

17. Nayak RK, Mahato KK, Routara BC, Ray BC. Evaluation of mechanical properties of $\mathrm{Al}_{2} \mathrm{O}_{3}$ and $\mathrm{TiO}_{2}$ nano filled enhanced glass fiber reinforced polymer composites. J Appl Polym Sci. 2016;133(47):44274. http://dx.doi.org/10.1002/app.44274.

18. Muralidhara B, Babu SPK, Suresha B. Studies on dynamic mechanical and thermal properties of boron arbide filled carbon fiber/epoxy composites. Mater Today Proc. 2021;46(Pt 19):9145-9. http://dx.doi.org/10.1016/j.matpr.2019.12.204.

19. Divya GS, Suresha B, Somashekar HM, Jamadar IM. Dynamic mechanical analysis and optimization of hybrid carbon-epoxy composites wear using taguchi method. Tribol Ind. 2020;43(2):298309.

20. Chowdhury FH, Hosur MV, Jeelani S. Investigations on the thermal and flexural properties of plain weave carbon/epoxynanoclay composites by hand-layup technique. J Mater Sci. 2007;42(8):2690-700. http://dx.doi.org/10.1007/s10853-0061370-3.

21. Zhou Y, Hosur M, Jeelani S, Mallick PK. Fabrication and characterization of carbon fiber reinforced clay/epoxy composite. J Mater Sci. 2012;47(12):5002-12. http://dx.doi.org/10.1007/ s10853-012-6376-4.

22. Muralidhara B, Babu SPK, Suresha B. Studies on the role of graphene nanoplatelets on mechanical properties, dynamicmechanical and thermogravimetric analysis of carbon-epoxy composites. J Inst Eng India Ser D. 2020. http://dx.doi. org/10.1007/s40033-020-00219-0.

23. Hossain MK, Chowdhury MMR, Bolden NW. Evaluation of thermo-mechanical properties of carbon/epoxy aminofunctionalized graphene nanoplatelet composite. Glob J Eng Sci. 2020;4(4):1-10.

24. Cai L, Al Ostaz A, Li X, Drzal LT, Rook BP, Cheng AHD, et al. Processing and mechanical properties investigation of epoxyimpregnated graphene paper. J Nanomech Micromech. 2016;6(3):04016005. http://dx.doi.org/10.1061/(ASCE) NM.2153-5477.0000108.

25. Patki AM, Goyal RK. Investigation of non-isothermal crystallization, dynamic mechanical and dielectric properties of poly(ether-ketone) matrix composites. Polym Technol Mater. 2021;60(1):70-83. http://dx.doi.org/10.1080/25740881.2020.1 786583 .

26. Joy J, George E, Thomas S, Anas S. Effect of filler loading on polymer chain confinement and thermomechanical properties of epoxy/boron nitride (h-BN) nanocomposites. New J Chem. 2020;44(11):4494-503. http://dx.doi.org/10.1039/C9NJ05834F.

27. Madeshwaran SR, Jayaganthan R, Velmurugan R, Gupta NK, Manzhirov AV. Mechanical and thermal properties of $\mathrm{MoS}_{2}$ reinforced epoxy nanocomposites. J Phys Conf Ser. 2018;991:12054. http://dx.doi.org/10.1088/1742-6596/991/1/012054.

28. Zhao M, Liu L, Zhang B, Sun M, Zhang X, Zhang X, et al. Epoxy composites with functionalized molybdenum disulfide nanoplatelet additives. RSC Advances. 2018;8(61):35170-8. http://dx.doi.org/10.1039/C8RA07448H.

29. Podsiadlo P, Kaushik AK, Arruda EM, Waas AM, Shim BS, Xu $\mathrm{J}$, et al. Ultrastrong and stiff layered polymer nanocomposites. Science. 2007;318(5847):80-3. http://dx.doi.org/10.1126/ science. 1143176 .

30. Kumaresan K, Chandramohan G, Senthilkumar M, Suresha B. Dynamic mechanical analysis and three-body wear of carbonepoxy composite filled with $\mathrm{SiC}$ particles. J Reinf Plast Compos. 2012;31(21):1435-48. http://dx.doi.org/10.1177/0731684412459250.

31. Adak NC, Chhetri S, Kim NH, Murmu NC, Samanta P, Kuila T. Static and dynamic mechanical properties of graphene oxideincorporated woven carbon fiber/epoxy composite. J Mater Eng Perform. 2018;27(3):1138-47. http://dx.doi.org/10.1007/ s11665-018-3201-5.

32. Wan YJ, Gong LX, Tang LC, Wu LB, Jiang JX. Mechanical properties of epoxy composites filled with silane-functionalized graphene oxide. Compos, Part AAppl Sci Manuf. 2014;64:7989. http://dx.doi.org/10.1016/j.compositesa.2014.04.023.

33. Tareq MS, Zainuddin S, Woodside E, Syed F. Investigation of the flexural and thermomechanical properties of nanoclay/ graphene reinforced carbon fiber epoxy composites. J Mater Res. 2019;34(21):3678-87. http://dx.doi.org/10.1557/jmr.2019.302. 
34. Loos MR, Coelho LAF, Pezzin SH, Amico SC. Effect of carbon nanotubes addition on the mechanical and thermal properties of epoxy matrices. Mater Res. 2008;11(3):347-52. http://dx.doi. org/10.1590/S1516-14392008000300019.

35. Bera T, Acharya SK, Mishra P. Synthesis, mechanical and thermal properties of carbon black/epoxy composites. Int $\mathrm{J}$ Eng Sci Technol. 2018;10(4):12. http://dx.doi.org/10.4314/ ijest.v10i4.2

36. Xue Y, Jin X, Fan Y, Tian R, Xu X, Li J, et al. Large-scale synthesis of hexagonal boron nitride nanosheets and their improvement in thermal properties of epoxy composites. Polym Compos. 2014;35(9):1707-15. http://dx.doi.org/10.1002/pc.22824.

37. Ayyanar S, Gnanavelbabu A, Rajkumar K, Loganathan P. Studies on high temperature wear and friction behaviour of AA6061/ $\mathrm{B}_{4} \mathrm{C} / \mathrm{hBN}$ hybrid composites. Met Mater Int. 2021;27:3040-57. http://dx.doi.org/10.1007/s12540-020-00710-z.

38. Weng Q, Wang X, Wang X, Bando Y, Golberg D. Functionalized hexagonal boron nitride nanomaterials: emerging properties and applications. Chem Soc Rev. 2016;45(14):3989-4012. http:// dx.doi.org/10.1039/C5CS00869G.

39. Jia D, Zhou L, Yang Z, Duan X, Zhou Y. Effect of preforming process and starting fused $\mathrm{SiO}_{2}$ particle size on microstructure and mechanical properties of pressurelessly sintered $\mathrm{BNp} / \mathrm{SiO}_{2}$ ceramic composites. J Am Ceram Soc. 2011;94(10):3552-60. http://dx.doi.org/10.1111/j.1551-2916.2011.04540.x.

40. Rathinasabapathy S, Santhosh MS, Asokan M. Significance of boron nitride in composites and its applications. In: Aydin M, editor. Recent advances in boron-containing materials. Rijeka: IntechOpen; 2020. http://dx.doi.org/10.5772/intechopen.81557

41. Li X, Zhu H. Two-dimensional $\mathrm{MoS}_{2}$ : properties, preparation, and applications. J Mater. 2015;1(1):33-44.

42. Apsarraj AD, Suresha B. Dynamic mechanical analysis and abrasive wear behavior of carbon-epoxy with molybdenum disulfide. In: International Conference on Innovations and Emerging Trends in Mechanical Engineering (IIETME-2014); 2014; Bangalore. Proceedings. Bangalore, India: Department of mechanical engineering, Nagarjuna college of engineering \& technology; 2014

43. Wattanakul K, Manuspiya H, Yanumet N. Thermal conductivity and mechanical properties of BN-filled epoxy composite: effects of filler content, mixing conditions, and BN agglomerate size. J Compos Mater. 2011;45(19):1967-80.

44. Weber WH, Merlin R. Raman scattering in materials science. Berlin, Heidelberg: Springer; 2000.

45. Socrates G. Infrared and Raman characteristic group frequencies: tables and charts. 3rd ed. Hoboken: John Wiley \& Sons, Inc.; 2004.

46. Farquharson S, Smith W, Rose J, Shaw M. Correlations between molecular (Raman) and macroscopic (rheology) data for process monitoring of thermoset composite. J Process Anal Chem. 2002; 7:45-53

47. Jang D, Lee DS, Lee A, Joh H-I, Lee S. Opto-thermal technique for measuring thermal conductivity of polyacrylonitrile based carbon fibers. J Ind Eng Chem. 2019;78:137-42. http://dx.doi. org/10.1016/j.jiec.2019.06.025.

48. Frey GL, Tenne R, Matthews MJ, Dresselhaus MS, Dresselhaus G. Raman and resonance Raman investigation of $\mathrm{MoS}_{2}$ nanoparticles. Phys Rev B Condens Matter Mater Phys. 1999;60(4):2883-92. http://dx.doi.org/10.1103/PhysRevB.60.2883.

49. Ferraro JR, Nakamoto K, Brown CW. Introductory Raman spectroscopy. 2nd ed. USA: Elsevier; 2003.
50. Nemanich RJ, Solin SA, Martin RM. Light scattering study of boron nitride microcrystals. Phys Rev B Condens Matter. 1981;23(12):6348-56. http://dx.doi.org/10.1103/PhysRevB.23.6348.

51. ASTM International. ASTM D7028-07. Standard test method for glass transition temperature ( $\mathrm{Tg}$ ) of polymer matrix composites by dynamic mechanical analysis (DMA). West Conshohocken: ASTM International; 2015.

52. Stark W. Investigation of the curing behaviour of carbon fibre epoxy prepreg by dynamic mechanical analysis. Polym Test. 2013;32(2):231-9. http://dx.doi.org/10.1016/j. polymertesting.2012.11.004.

53. Azimpour-Shishevan F, Akbulut H, Mohtadi-Bonab MA. Synergetic effects of carbon nanotube and graphene addition on thermomechanical properties and vibrational behavior of twill carbon fiber reinforced polymer composites. Polym Test. 2020;90:106745. http://dx.doi.org/10.1016/j.polymertesting.2020.106745.

54. Ghosh P, Bose NR, Mitra BC, Das S. Dynamic mechanical analysis of FRP composites based on different fiber reinforcements and epoxy resin as the matrix material. J Appl Polym Sci. 1997;64(12):2467-72.

55. Goertzen WK, Kessler MR. Dynamic mechanical analysis of carbon/epoxy composites for structural pipeline repair. Compos, Part B Eng. 2007;38(1):1-9.

56. Murugan R, Ramesh R, Padmanabhan K. Investigation on static and dynamic mechanical properties of epoxy based woven fabric glass/carbon hybrid composite laminates. Procedia Eng. 2014;97:459-68. http://dx.doi.org/10.1016/j.proeng.2014.12.270.

57. Hameed N, Sreekumar PA, Valsaraj VS, Thomas S. Highperformance composite from epoxy and glass fibers: morphology, mechanical, dynamic mechanical, and thermal analysis. Polym Compos. 2009;30(7):982-92. http://dx.doi.org/10.1002/pc.20644.

58. Chartoff RP, Menczel JD, Dillman SH. Dynamic mechanical analysis (DMA). In: Menczel JD, Prime RB, editors. Thermal Analysis of Polymers. Hoboken, USA: John Wiley \& Sons, Inc.; 2008. http://dx.doi.org/10.1002/9780470423837.ch5

59. Hill L. Dynamic mechanical and tensile properties. In: Koleske J, editor. Paint and Coating Testing Manual. 15th ed. West Conshohocken, PA: ASTM International; 2012.

60. Ralph E. Wright. Thermosets, reinforced plastics, and composites. In: Harper Charles A, editor. Handbook of plastics, elastomers, and composites. New York: McGraw-Hill; 2002.

61. Saba N, Jawaid M. A review on thermomechanical properties of polymers and fibers reinforced polymer composites. J Ind Eng Chem. 2018;67:1-11. http://dx.doi.org/10.1016/j.jiec.2018.06.018.

62. Prime RB, Bair HE, Vyazovkin S, Gallagher PK, Riga A. Thermogravimetric analysis (TGA). In: Menczel JD, Prime RB, editors. Thermal analysis of polymers. Hoboken, USA: John Wiley \& Sons, Inc.; 2008. http://dx.doi.org/10.1002/9780470423837. ch3.

63. Yu C, Zhang J, Li Z, Tian W, Wang L, Luo J, et al. Enhanced through-plane thermal conductivity of boron nitride/epoxy composites. Compos, Part A Appl Sci Manuf. 2017;98:25-31. http://dx.doi.org/10.1016/j.compositesa.2017.03.012.

64. Grund D, Orlishausen M, Taha I. Determination of fiber volume fraction of carbon fiber-reinforced polymer using thermogravimetric methods. Polym Test. 2019;75:358-66. http://dx.doi.org/10.1016/j.polymertesting.2019.02.031.

65. Wang D, Zhou K, Yang W, Xing W, Hu Y, Gong X. Surface modification of graphene with layered molybdenum disulfide and their synergistic reinforcement on reducing fire hazards of epoxy resins. Ind Eng Chem Res. 2013;52(50):17882-90. http://dx.doi.org/10.1021/ie402441g. 